\title{
Laboreal
}

Volume $11 \mathrm{~N}^{\circ} 1$ | 2015

Modos de vida e trabalho

\section{Um modelo de investigação coletiva e internacional acerca da segurança: contribuição para a história das pesquisas sobre segurança do trabalho: sinopse da pesquisa da CECA sobre a segurança na siderurgia (1962-1966)}

Un modelo de investigación colectiva e internacional sobre la seguridad:

Contribución a la historia de las investigaciones sobre seguridad en el trabajo: resumen de la investigación CECA sobre la seguridad en la siderurgia (1962-1966) Un modèle de recherche collective et internationale sur la sécurité: Contribution à l'histoire des recherches sur la sécurité du travail : un aperçu de la Recherche de la CECA sur la sécurité dans la sidérurgie (1962-1966)

A group and international research model about safety: Contribution for the history of researches on safety at work: an overview of the ESCS research on safety in the steel industry (1962-1966)

\section{Jacques Leplat}

Tradutor. João Viana Jorge

\section{OpenEdition} Journals

\section{Edição electrónica}

URL: http://journals.openedition.org/laboreal/4428

DOI: $10.4000 /$ laboreal. 4428

ISSN: 1646-5237

\section{Editora}

Universidade do Porto

\section{Refêrencia eletrónica}

Jacques Leplat, « Um modelo de investigação coletiva e internacional acerca da segurança: contribuição para a história das pesquisas sobre segurança do trabalho: sinopse da pesquisa da CECA sobre a segurança na siderurgia (1962-1966) », Laboreal [Online], Volume 11 №1 | 2015, posto online no dia 01 julho 2015, consultado o 24 setembro 2020. URL : http://journals.openedition.org/ laboreal/4428; DOI : https://doi.org/10.4000/laboreal.4428

Este documento foi criado de forma automática no dia 24 setembro 2020.

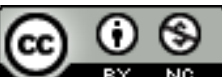

Laboreal está licenciado com uma Licença Creative Commons - Atribuição-NãoComercial 4.0 Internacional. 


\section{Um modelo de investigação coletiva e internacional acerca da segurança: contribuição para a história das pesquisas sobre segurança do trabalho: sinopse da pesquisa da CECA sobre a segurança na siderurgia (1962-1966)}

Un modelo de investigación colectiva e internacional sobre la seguridad: Contribución a la historia de las investigaciones sobre seguridad en el trabajo: resumen de la investigación CECA sobre la seguridad en la siderurgia (1962-1966) Un modèle de recherche collective et internationale sur la sécurité: Contribution à l'histoire des recherches sur la sécurité du travail : un aperçu de la Recherche de la CECA sur la sécurité dans la sidérurgie (1962-1966)

A group and international research model about safety: Contribution for the history of researches on safety at work: an overview of the ESCS research on safety in the steel industry (1962-1966)

Jacques Leplat

Tradução : João Viana Jorge 


\section{REFERÊNCIA}

CECA. (1969). Recherche communautaire sur la sécurité des mines et la sidérurgie (1962-1966). Communauté Européenne du charbon et de l'Acier (CECA). Etudes de physiologie et de psychologie du travail, ${ }^{\circ} 4,1969$, pp. 13-24.

\section{NOTA DO EDITOR}

http://dx.doi.org/10.15667/laborealxi0115jl

1 As pesquisas sobre segurança das pessoas nos diversos trabalhos a que estão associadas têm uma longa história, frequentemente invocada nas numerosas obras consagradas à segurança. A psicologia moderna traduz também essa preocupação como testemunha, nomeadamente, a literatura da psicologia dita aplicada desde o fim do século XIX. A França forneceu contribuições importantes para estas pesquisas, como atestam, nomeadamente, os trabalhos levados a cabo ou dirigidos por Lahy, Pacaud, Reuchlin, Faverge no século XX. As pesquisas iniciais foram sobretudo orientadas com referência à psicologia diferencial, com o uso frequente de testes. $O$ aperfeiçoamento da segurança foi procurado na perspectiva da melhoria da adaptação do homem à sua tarefa. Porém, após a segunda guerra mundial desenvolveram-se correntes de pesquisa visando estender o campo da psicologia do trabalho no âmbito do estudo da segurança: dizendo de modo resumido, o interesse deixou de se centrar apenas na adaptação do homem ao seu trabalho, orientando-se para a questão da adaptação do trabalho ao homem e, finalmente, para a concepção de situações de trabalho geradoras de uma melhor articulação das condições humanas, organizacionais, técnicas e sociais adequadas à criação de um ambiente de trabalho mais seguro. 0 texto aqui apresentado inscreve-se nesse período de transição e permite detectar melhor a natureza e as modalidades das evoluções ulteriores.

2 A breve apresentação deste texto está organizada em duas partes. A primeira especifica o conjunto no qual se inscreve e a segunda fornece algumas justificações da escolha da parte do Documento que se reteve para publicação neste número de Laboreal.

\section{0 contexto do texto}

O texto aqui apresentado é pois relativo a pesquisas conduzidas no quadro de um vasto programa intitulado "Recherche communautaire sur la sécurité dans les mines et la sidérurgie " : refere-se à parte respeitante à siderurgia, sendo distinta e conduzida por uma outra equipa a respeitante às minas. As pesquisas relatadas nesses documentos estão relacionadas com «acções empreendidas pela Alta Autoridade da CECA (Comunidade Europeia do Carvão e do Aço) para o progresso das pesquisas sobre prevenção de acidentes» (p. 5) ${ }^{1}$. A sua concepção dá sequência a pesquisas anteriores oriundas de um programa elaborado em 1959. Tal como este último, o programa sobre o qual nos debruçamos foi preparado através de colaborações entre organizações profissionais e Institutos de Investigação de cinco países-membros da CECA de então : 
Alemanha, França Itália, Bélgica e Países Baixos. Faverge desempenhou um importante papel na elaboração desse programa que foi colectivamente preparado e cuja realização se escalonou entre 1962 e 1966. Tratava-se realmente duma pesquisa colectiva periodicamente ponteada por reuniões, que agrupavam todas as equipas no Luxemburgo para discussões durante dois dias que asseguravam assim uma coordenação do desenrolar das pesquisas. Tinham também sido organizadas visitas aos locais em que as pesquisas se desenvolviam. No final dessas pesquisas foi estabelecido um relatório de síntese para cada equipa nacional e designado um coordenador para a redacção do relatório de síntese geral. É deste último relatório de 231 páginas que o presente texto foi extraído.

Os campos de pesquisa escolhidos por cada equipa eram diferentes.

- Alemanha: laminadores, fundições, acabamentos.

- Bélgica : altos-fornos.

- França : transportes.

- Itália: laminadores.

- Países-Baixos: reparações.

Os títulos dos diferentes capítulos do relatório demonstram bem a diversidade dos temas abordados.

- Recolha e exploração preliminar de informações sobre a segurança e o trabalho.

- Organização do trabalho.

- A segurança e o grupo de trabalho.

- Instrumentos e condições de trabalho.

- Características individuais.

- Propostas concretas para a melhoria da prevenção de acidentes.

\section{Justificação e conteúdo do texto}

O documento do qual este texto foi extraído relata os trabalhos executados no decurso dos anos '60, numa época em que o estudo dos acidentes se centrava ainda nas características das pessoas neles implicados. Desde o fim do século XIX era esta a concepção vigente e explanada em múltiplas publicações como atesta, por exemplo, uma bibliografia dos trabalhos de Lahy (1872-1943) elaborada por Turbiaux (1982-3). 0 «factor humano» era nomeadamente explorado para a selecção de agentes diversos, em particular condutores de comboios e de maquinaria variada. Um artigo, particularmente bem documentado, publicado por Lahy e Korngold Pacaud, em 1936, intitulado « Recherches expérimentales sur les causes psychologiques des accidents du travail», ilustra bem esta concepção do acidente. Vejam-se por exemplo alguns elementos dos títulos das suas diferentes partes : $\mathrm{O}$ factor humano em geral e o factor individual nos acidentes de trabalho; A tese da «predisposição» estudo da fatigabilidade; A prática da selecção preventiva. Nesta mesma publicação pode ler-se que em 1928, no congresso internacional de psicotécnica, a calamidade dos acidentes foi comparada à das doenças e devia assim relevar de uma profilaxia análoga.

7 É numa perspectiva completamente diferente que irá ser concebida a pesquisa CECA. 0 seu documento preparatório, que tinha sido redigido por uma equipa englobando representantes dos meios profissionais, científicos e governamentais, «exprimia o desejo de que em vez dum estudo abarcando um campo muito vasto se optasse por um 
outro incidindo sobre efectivos limitados, escolhidos numa determinada unidade operacional» (p. 11). Ao mesmo tempo sublinhava-se a «necessidade de uma análise muito concreta das condições da actividade e de um esforço para interligar o acidente com as próprias condições de trabalho» (id.). Era igualmente solicitado que essa limitação do campo de extensão orientasse a investigação para uma verdadeira análise dos mecanismos geradores dos acidentes e permitisse assim extrair aplicações precisas no plano da segurança no trabalho» (id.). As pesquisas relatadas no presente texto aderiram a estes princípios que se destacavam, nessa época, pela sua originalidade e exprimiam uma rotura com as pesquisas anteriores. Às pesquisas centradas no papel do operador, sucediam as centradas em situações de trabalho e a entrada em linha de conta das suas diversas dimensões: psicológica, técnica, organizacional, sociológica, social. Em outras publicações da CECA dessa época encontram-se as mesmas características. Por exemplo, um fascículo colectivo da mesma colecção intitula-se «Fiabilité et sécurité » (1972) e comporta textos de síntese que colocam a tónica nos incidentes tanto quanto nos acidentes e atribuem uma importância acrescida às condições organizacionais. Todos esses trabalhos iriam contribuir para a renovação dos quadros da pesquisa em segurança do trabalho. Sendo limitado o espaço reservado à publicação do presente texto, tornava-se necessário escolher um extracto dessa obra que dela revelasse os traços originais mais característicos. Pareceu assim que a parte introdutória intitulada «considerações gerais sobre os trabalhos da pesquisa comunitária», que define as exigências, forneceria os elementos essenciais para a sua apresentação. Extraímos portanto os elementos mais originais, aplicando alguns cortes destinados a eliminar as passagens respeitantes a conhecimentos mais clássicos. 0 leitor interessado neste texto encontrará no Documento referido desenvolvimentos que se mantiveram até hoje cheios de interesse.

\section{BIBLIOGRAFIA}

Chesnay, M. (2013). L'Arbre des causes : Histoire des fondements et usages de la méthode. In C. Teiger et M. Lacomblez (Se) Former pour transformer le travail (pp. 470-478). Laval, Presses de l'Université Laval.

Faverge, J.-M. (1967). Psychosociologie des accidents du travail. P.U.F. Paris.

Faverge, J.-M. (1972). Les accidents du travail in M. Reuchlin (Ed.). Traité de Psychologie Appliquée (pp. 223-262). t. 3. P.U.F. : Paris.

Lahy, J.-M. et Pacaud Korngold S. (1936). Recherches expérimentales sur les causes psychologiques des accidents du travail. Le Travail Humain, SérieB, 1, 1-73.

Leplat, J. (1985). Erreur humaine, fiabilité humaine dans le travail. A. Colin : Paris.

Leplat, J. (2013). Contribution de S. Pacaud à l'étude des accidents. Dans R. Ouvrier-Bonnaz \& A. Weill-Fassina (2013). Suzanne Paccaud (1902-1988). De la psychotechnique à l'ergonomie (coord.) (pp. 252-293). Toulouse : Octares/Lettropolis. (edição eletrónica).

Metz, B. et Lederman, S. (1960). Les accidents du travail et l'alcool. Population, 2 (sem paginação). 
Turbiaux, M. (1982-3). J.M. Lahy (1872-1943) Essai de bio-bibliographie. Bulletin de psychologie, 362, 969-985

\section{NOTAS}

1. Esta paginação e a que segue remetem para o documento de referência do qual se extraiu o texto.

\section{AUTORES}

\section{JACQUES LEPLAT}

Groupe de Recherche et d'Etude sur l'Histoire du Travail et de L'Orientation (GRESHTO), Centre de Recherche sur le Travail et le Développement (CRTD), Conservatoire National des Arts et Métiers (CNAM), 41, Rue Gay Lussac 75005 Paris, France jacques.leplat@wanadoo.fr 